\title{
More on Patients Expectations and Success with Bariatric Surgery
}

\author{
Antonio E. Pontiroli ${ }^{1} \cdot$ Valerio Ceriani $^{2} \cdot$ Franco Folli $^{1}$ \\ Published online: 1 February 2018 \\ (C) Springer Science+Business Media, LLC, part of Springer Nature 2018
}

\section{Dear Editor,}

We deeply appreciated the letter by Pouwels, Smelt, and Smulders and the enclosed comments and statements [1] in connection to our previous letter [2]. As the authors state, when addressing patient expectations, a multidisciplinary approach is required, where psychologists and educators probably play the major role. There are ample reasons to use new technology opportunities, be it web-based approach [3], or social networks [4], as well as traditional bariatric care groups [2]. The methods chosen can depend on local facilities and cultural attitudes. However, one should also consider the validity of the messages conveyed, and we are afraid that in the past several messages were probably not adequately received by people, be it bariatric patients, or general population. For instance, although educated people used to have a healthier lifestyle than less educated people [5], from 1988 to 2006 in the USA, there was a significant halving of adherence to healthy lifestyle habits [6]. Therefore, a great effort is required to improve knowledge and to induce correct expectations in bariatric patients, and methods and contents of the messages should be modernized together.

\section{Compliance with Ethical Standards}

Conflict of Interest The authors declare that they have no conflict of interest.
Ethical Approval This article does not contain any studies with human participants or animals performed by any of the authors.

Informed Consent Does not apply.

\section{References}

1. Pouwels S, Smelt HJM, Smulders JF. Reply to: 'Patients' expectations are important for success in bariatric surgery. Obes Surg. 2018.

2. Pontiroli AE, Ceriani V, Folli F. Patients' expectations are important for success in bariatric surgery. Obes Surg. 2017;27(9):2469-70. https://doi.org/10.1007/s11695-017-2788-1.

3. Raaijmakers LC, Pouwels S, Berghuis KA, et al. Technology-based interventions in the treatment of overweight and obesity: a systematic review. Appetite. 2015;95:138-51. https://doi.org/10.1016/j.appet. 2015.07.008.

4. Hales S, Turner-McGrievy GM, Wilcox S, et al. Social networks for improving healthy weight loss behaviors for overweight and obese adults: a randomized clinical trial of the social pounds off digitally (Social POD) mobile app. Int J Med Inform. 2016;94:81-90. https:// doi.org/10.1016/j.ijmedinf.2016.07.003.

5. Mokdad AH, Bowman BA, Ford ES, et al. The continuing epidemics of obesity and diabetes in the United States. JAMA. 2001;286(10): 1195-200. https://doi.org/10.1001/jama.286.10.1195.

6. King DE, Mainous AG 3rd, Carnemolla M, Everett CJ. Adherence to healthy lifestyle habits in US adults, 19882006. Am J Med 2009; 122: 528-534, 6, https://doi.org/10. 1016/j.amjmed.2008.11.013.
Antonio E. Pontiroli

antonio.pontiroli@unimi.it

Valerio Ceriani

valerio.ceriani@multimedica.it

Franco Folli

franco.folli@unimi.it

1 Dipartimento di Scienze della Salute, Università degli Studi di Milano, Ospedale San Paolo, Milan, Italy

2 Istituto Multimedica, Milan, Italy 